4 Troosters T, Gosselink R, Decramer M. Six minute walking distance in healthy elderly subjects. Eur Respir J 1999; 14: 270-274.

5 Gibbons WJ, Fruchter N, Sloan S, Levy RD. Reference values for a multiple repetition 6 minute walk test in healthy adults older than 20 year. J Cardiopulm Rehabil 2001; 21: 87-93.

DOI: 10.1183/09031936.05.00070105

\section{From the authors:}

I. García-Talavera's reaction to the results of our trial of ambulatory oxygen (AO) in oxygen-dependent chronic obstructive pulmonary disease (COPD) is of no surprise to us. We realise that our findings, i.e. that as-needed $\mathrm{AO}$ provided for a period of 3 months had no effect on quality of life and walked distance [1], are against the stream of current guidelines (i.e. that active patients receiving long-term oxygen therapy should have both stationary and mobile systems of oxygen delivery) [2, 3].

Negative trials are often inconclusive because of imprecise estimates of treatment effects that leave uncertainty about their conclusions [4]. However, the width of the observed confidence intervals around the mean responses, and their relation to the respective minimal clinically important differences, are clear indications that the sample size of our trial does not explain its negative results. Should we repeat this experiment in 100 different samples of patients with oxygen-dependent COPD, we would find 95 times that the treatment effect of $\mathrm{AO}$ is smaller than what is usually considered clinically significant [5]. This is evidence-based medicine.

Other issues raised by I. García-Talavera relate to the variations of oxygen saturation during the 6-minute walk test and the mean arterial oxygen tension $\left(\mathrm{Pa}_{\mathrm{a}} \mathrm{O}_{2}\right)$ of our patients. We studied patients with oxygen-dependent COPD. The mean $\mathrm{Pa}_{1} \mathrm{O}_{2}$ (7.0 $\mathrm{kPa}$ (53 mmHg); SD: 4) is a reflection of the trial inclusion criteria. All were desaturated during the baseline, and walk test was performed while breathing room air (mean nadir: $83 \%$; SD: 5). AO was titrated to maintain a saturation $\geqslant 90 \%$ during ambulation. It is our experience that patients with more severe hypoxaemia have more advanced disease and are more often house-bound. Whether the results of a similar trial would be different in patients with more severe hypoxaemia is possible but, in our opinion, unlikely. This remains to be seen.

We do not negate that a small proportion of patients with oxygen-dependent chronic obstructive pulmonary disease could really benefit from ambulatory oxygen. Our challenge is to identify these patients. Unfortunately, acute response to ambulatory oxygen does not predict long-term improvement in quality of life in patients with chronic obstructive pulmonary disease not fulfilling criteria for long-term oxygen therapy, but with exertional desaturation $[5,6]$. We came to the same conclusion in oxygen-dependent chronic obstructive pulmonary disease following secondary (and as yet unpublished) analyses of our data.

\section{Y. Lacasse and F. Maltais}

Centre de recherche, Centre de pneumologie, Institut universitaire de cardiologie et de pneumologie de l'Université Laval, Québec, Canada.

\section{REFERENCES}

1 Lacasse Y, Lecours R, Pelletier C, Bégin R, Maltais F. Randomised trial of ambulatory oxygen in oxygen-dependent COPD. Eur Respir J 2005; 25: 1032-1038.

2 Celli BR, MacNee W, ATS/ERS Task Force. Standards for the diagnosis and treatment of patients with COPD: a summary of the ATS/ERS position paper. Eur Respir J 2004; 23: 932-946.

3 National Collaboration Centre for Chronic Conditions. Chronic obstructive pulmonary disease: national clinical guideline for management of chronic obstructive pulmonary disease in adults in primary and secondary care. Thorax 2004; 59: Suppl. 1, 1-232.

4 Detsky AS, Sackett DL. When was a "negative" clinical trial big enough? How many patients you needed depends on what you found. Arch Intern Med 1985; 145: 709-712.

5 Man-Son-Hing M, Laupacis A, O'Rourke K, et al. Determination of the clinical importance of study results: a review. J Gen Intern Med 2002; 17: 469-476.

6 Eaton T, Garrett JE, Young P, et al. Ambulatory oxygen improves quality of life of COPD patients: a randomised controlled study. Eur Respir J 2002; 20: 306-312.

DOI: $10.1183 / 09031936.05 .00082405$

\title{
Cystic lesions of the lung: a forgotten menace
}

\section{To the Editors:}

We read with interest the article by BATTISTINI et al. [1] concerning a young female with spontaneous pneumothorax as the presenting feature of pulmonary lymphangioleiomyoma, which appeared in a previous issue of the European Respiratory Journal. The differential diagnoses, which included lymphangioleiomyoma, tuberous sclerosis and Langerhans cell histiocytosis or eosinophilic granuloma, were based on bilateral cystic pulmonary lesions on high-resolution computed tomography, which were slow to progress, as well as the relatively normal pulmonary function tests [2].

We recall a 46-yr-old male who presented to us with left spontaneous pneumothorax, followed 2 days later by the development of contralateral pneumothorax. A computed 